\title{
Defining quality in the surgical care of lung cancer patients
}

\author{
Whitney S. Brandt, MD, James M. Isbell, MD, MSCI, and David R. Jones, MD
}

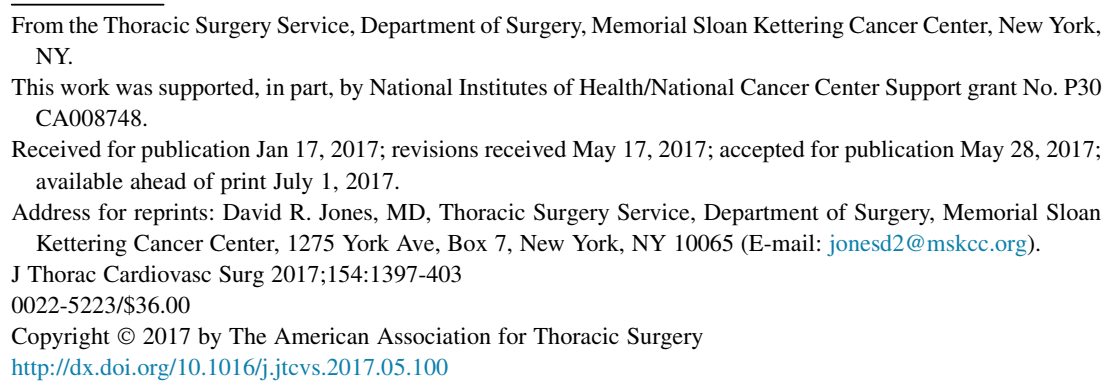

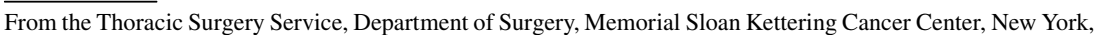
NY.

This work was supported, in part, by National Institutes of Health/National Cancer Center Support grant No. P30 CA008748.

Received for publication Jan 17, 2017; revisions received May 17, 2017; accepted for publication May 28, 2017; available ahead of print July 1, 2017

Address for reprints: David R. Jones, MD, Thoracic Surgery Service, Department of Surgery, Memorial Sloan

Kettering Cancer Center, 1275 York Ave, Box 7, New York, NY 10065 (E-mail: jonesd2@mskcc.org).

J Thorac Cardiovasc Surg 2017;154:1397-403

$0022-5223 / \$ 36.00$

Copyright (C) 2017 by The American Association for Thoracic Surgery

http://dx.doi.org/10.1016/j.jtcvs.2017.05.100

The challenge of defining, measuring, and delivering highquality care in the management of patients with lung cancer is complex. ${ }^{1}$ The challenges to codifying and implementing quality-of-care metrics are, in large part, a result of different perspectives of providers, payers, hospitals, and patients regarding the definition of quality and how to achieve it across multiple health care delivery systems and different socioeconomic groups. Primary drivers of the quality movement in oncology include the escalating costs associated with cancer care delivery and the increasing awareness that much of that care is neither evidence-based nor patient-centered. The annual direct cost of cancer care in the United States is $\$ 125$ billion (in 2010 dollars) and is expected to reach $\$ 173$ billion by 2020 , an unsustainable increase of $38 \% .^{2,3}$ Efforts by payers and the government to decrease costs while retaining excellent outcomes are accelerating, and the implementation of such programs is imminent.

We believe that the imperative to improve quality in lung cancer care offers thoracic oncologic surgeons an opportunity to establish robust quality and valueconscious programs. Multiple organizations-such as the National Quality Forum, the American College of Surgeons Commission on Cancer, and the Centers for Medicare and Medicaid Services-and consensus-based practice guidelines from the National Comprehensive Cancer Network (NCCN) and others ${ }^{4}$ provide suggestions on what constitutes quality surgical care of patients with lung cancer. The Society of Thoracic Surgeons (STS) has recently begun to examine quality metrics surrounding lung resection in a more robust manner using the STS General Thoracic Surgery Database, whereas the European Society of Thoracic Surgeons (ESTS) has been publishing guidelines and recommending quality metrics for more than a decade. , $6^{5}$

Herein, we examine several-although, by no means all-elements of quality and value in the surgical care of patients with lung cancer, including, when possible, the Donabedian classification of structure, process, and outcomes. ${ }^{7}$ However, we stratify the continuum of surgical of this review.

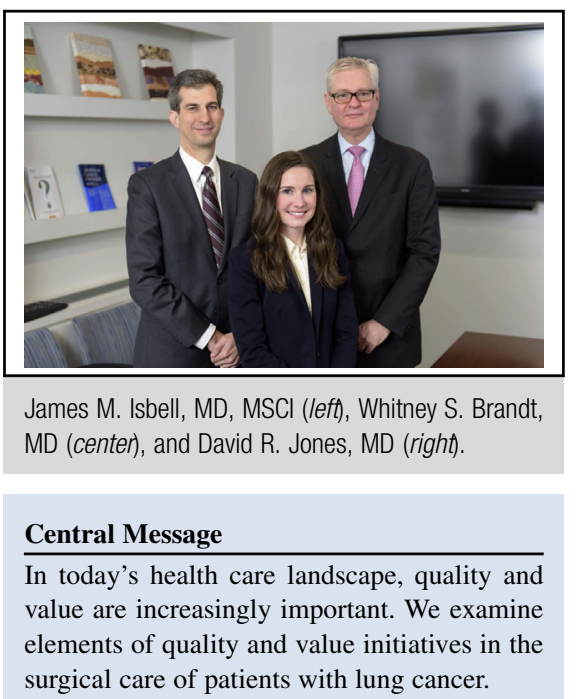

See Editorial Commentary page 1404.

See Editorial page 1395.

care into preoperative, intraoperative, and postoperative components, with the realization that there are overlapping indicators and measures of quality across these segments of care. Finally, in the scope of this review, we primarily focus on the surgical care of patients with early stage lung cancer and less on management of late-stage disease, including chemotherapy, immunotherapy, or targeted therapy. In addition, although it is becoming increasingly important, the role of patient reported outcomes is beyond the scope

\section{ELEMENTS OF QUALITY AND VALUE \\ Preoperative Assessment}

At a minimum, preoperative evaluation should include computed tomography (CT) imaging to ascertain resectability and the extent of the resection required, pulmonary function testing to assess a patient's ability to tolerate the planned resection, and an assessment of a patient's performance status. ${ }^{8}$ Previous studies have demonstrated that current smokers have a longer length of stay and increased risk of postoperative pulmonary complications. ${ }^{8,9}$ Therefore, smoking cessation should be strongly encouraged, and a program should be in place to provide support with both counseling and approved pharmacologic adjuncts. $^{8,10,11}$

All patients being considered for pulmonary resection should undergo preoperative pulmonary function testing, 
including spirometry and diffusion capacity. ${ }^{12,13}$ Predicted postoperative forced expiratory volume in 1 second and diffusing capacity of the lungs for carbon monoxide should be calculated. Patients with a predicted postoperative value $<40 \%$ for either measurement should be considered high-risk for lobectomy and should be offered either sublobar resection or nonsurgical therapy. For selected patients with marginal pulmonary function testing results, cardiopulmonary exercise testing can be performed to assess suitability for resection.

In general, preoperative cardiac testing should be limited to patients with significant risk factors for cardiac disease. Although no randomized studies have evaluated the role of preoperative coronary revascularization before lung resection, randomized trials from the vascular surgery population-an arguably similar group of patients to those undergoing lung resection-do not support preoperative revascularization for patients with stable cardiac disease. ${ }^{14}$ The American College of Cardiology and the American Heart Association have jointly published guidelines for the perioperative evaluation of patients undergoing noncardiac surgery. ${ }^{15}$

The STS and National Quality Forum endorse recording performance status and clinical stage before lung resection as preoperative process measures. Reduced preoperative performance status has been associated with an increased perioperative risk of morbidity and mortality. ${ }^{5}$ Similarly, clinical stage has been linked to short- and long-term postoperative outcomes. As such, both of these measures should be recorded for all patients undergoing lung resection for presumed or biopsy-proven lung cancer.

\section{Preoperative Staging}

In a retrospective study of the Surveillance, Epidemiology, and End Results (SEER) database, Ost and colleagues $^{16}$ evaluated patients with lung cancer with regional spread but without evidence of metastatic disease and found that only $21 \%$ had a diagnostic evaluation consistent with the established guidelines. Only $56 \%$ of patients in this study underwent mediastinal sampling before treatment. ${ }^{16}$ Farjah and colleagues $^{17}$ also demonstrated reduced survival among Medicare recipients who did not receive preoperative mediastinal staging in accordance with the existing guidelines.

Several clinical guidelines for preoperative staging exist, but the most comprehensive are those published by the NCCN (Table 1). ${ }^{18}$ In addition to a CT scan of the chest and upper abdomen, a positron-emission tomography/CT scan should be obtained to assess for evidence of metastatic disease. Pathologic mediastinal lymph node evaluation should be performed before lung resection for central stage IA tumors and all stage IB to stage IIIA tumors, using the least-invasive means possible. Pathologic mediastinal staging should also be performed for peripheral stage IA tumors when there is hilar or mediastinal adenopathy and/ or fluorodeoxyglucose avidity in these lymph nodes on positron-emission tomography scan. ${ }^{18}$ The ESTS has developed detailed, evidenced-based guidelines for the preoperative staging of mediastinal lymph nodes in patients with non-small cell lung cancer (NSCLC). ${ }^{19}$

In accordance with NCCN guidelines, a magnetic resonance imaging brain scan with contrast should be obtained preoperatively for all patients with small cell lung cancer or stage II to stage IV NSCLC, to assess for evidence of brain metastasis. ${ }^{18}$ For cases where brain magnetic resonance imaging is not available or not possible, a head CT with contrast is recommended.

\section{Intraoperative Quality Measures}

Surgical approach. The differences between open and minimally invasive approaches such as video-assisted thoracic surgery (VATS) or robot-assisted VATS have been widely researched. Multiple retrospective studies have demonstrated that VATS lobectomy is associated with shorter lengths of hospital stay ${ }^{20}$ and decreased morbidity and mortality compared with open approaches. ${ }^{21,22}$ An analysis of the STS database demonstrated that minimally invasive resection of lung cancer resulted in a $50 \%$ reduction in major complications, compared with thoracotomy, adjusted for age, sex, and comorbidities. ${ }^{23}$ A recent propensitymatched analysis of prospectively collected Cancer and Leukemia Group B (CALGB) 140202 data demonstrated that minimally invasive lobectomy resulted in shorter hospital length of stay, fewer complications, and greater likelihood of independent discharge to home, compared with open lobectomy, for early stage lung cancer. ${ }^{24}$ Despite these findings, there have been no reported differences in overall survival, disease-specific survival, or progressionfree survival in patients who underwent minimally invasive lobectomy versus open thoracotomy. Therefore, minimally invasive approaches have significant early advantages for patient care; however, the current literature does not support the oncologic superiority of one approach over the other.

Cost of procedure has become an increasingly important consideration when assessing quality in this new era of value-driven care. A comparison of costs between VATS lobectomy and thoracotomy found that VATS lobectomy costs about \$3476 less than thoracotomy. This cost difference was attributed primarily to shorter length of stay in the VATS cohort. ${ }^{25}$ Compared with those for traditional VATS, the current costs for robot-assisted VATS make it less appealing from a pure value proposition perspective. $^{26}$ Moreover, a recent meta-analysis demonstrated equivalency in both short- and long-term outcomes for these 2 minimally invasive approaches. ${ }^{27}$ Therefore, at present the cost differential and the similar 
early benefits in patient care suggest that VATS offers the best value (cost/outcome) of these 2 approaches; however, robot-assisted VATS remains a relatively new technology, and with time and increased robotic platform competition costs will likely decrease.

Resection and margins. Although no prospective trials have compared outcomes between R0 and R1 resection, $\mathrm{R} 1$ resection is an independent predictive factor for poor prognosis and is associated with lower 5-year overall survival. ${ }^{28}$ A recent best evidence analysis of $>400$ reports suggested that, following incomplete resection, patients with microscopic (R1) or nodal residual disease have a survival advantage over those with macroscopic residual (R2) disease. ${ }^{29}$ To minimize the incidence of recurrence and to raise awareness about the importance of achieving negative margins, we recommend institutional tracking and scheduled review of R1 and R2 resections for lung cancer, preferably stratified by type of resection.

Surgeons must decide the most oncologically superior type of resection to perform. Lung Cancer Study Group 821 established lobectomy as the current standard of care for early stage, node-negative operable lung cancer. ${ }^{30}$ The majority of contemporary publications show a significant reduction in overall and disease-free survivals when sublobar resection is performed instead of lobectomy. ${ }^{31,32}$ Furthermore, examination of the National Cancer Database (NCDB) (2003-2011) revealed that patients with cT1 N0 M0 tumors undergoing sublobar resection were more likely to receive inadequate lymphadenectomy and have positive margins. ${ }^{32}$ CALGB 140503 and Japan Clinical Oncology Group 0802 are prospective, randomized noninferiority trials examining lobectomy versus sublobar resection; mature results are due after 2020. Japan Clinical Oncology Group 0802 permits only segmentectomy, whereas CALGB 140503 permits wedge resection and segmentectomy, which may make interpretation of the results more challenging. Until the mature results of these clinical trials are published, the best level-1 evidence-although it is older-demonstrates that lobectomy offers the largest oncologic benefit for patients with early stage lung cancer. For patients who are not candidates for lobectomy, the preponderance of level-2 evidence suggests that segmentectomy is oncologically superior to wedge resection for the treatment of smaller tumors. ${ }^{31,33}$ Additional evidence and current American College of Chest Physicians guidelines suggest that patients who cannot tolerate lobectomy are candidates for sublobar resection or stereotactic body radiation therapy. ${ }^{34,35}$

Resection margin is a useful intraoperative quality metric with relevance to tumor recurrence, particularly in sublobar resections. A comprehensive retrospective analysis demonstrated that, in patients with tumors smaller than $2 \mathrm{~cm}$ who underwent wedge resection for NSCLC, the risk of local recurrence was significantly decreased with increasing margin distance up to $15 \mathrm{~mm} \cdot{ }^{36}$ Additional studies of patients who underwent segmentectomy found that margins $\leq 1 \mathrm{~cm}$ were associated with an increased risk of local recurrence. ${ }^{37}$ These data and the findings from other studies support efforts to achieve a resection margin of $\geq 2 \mathrm{~cm}$ in patients undergoing surgery for NSCLC.

Lymph node evaluation. Adequate lymph node evaluation is among the most critical elements of a quality lung cancer operation. As Osarogiagbon and colleagues showed in their examination of several large databases, ${ }^{38}$ including the California Cancer Registry, the SEER database, and the NCDB, appropriate pathologic nodal staging of NSCLC is critically underutilized. Since then, multiple retrospective studies have been performed. The findings demonstrate that, in $\mathrm{pN} 0$ resection specimens, a median of 5 lymph nodes were examined ${ }^{39}$; in $12 \%$ of all resections, and in $18 \%$ of all node-negative resections, no lymph nodes were examined ${ }^{39-42}$; among pN0 cases, $12 \%$ had no N1 lymph nodes examined ${ }^{43}$; in $42 \%$ of resections, and in $62 \%$ of mediastinal lymph node-negative cases, no mediastinal lymph nodes were examined. . $^{39,40,44,45}$

Multiple guidelines on what constitutes an adequate nodal dissection are available to intraoperatively guide surgeons (Table 2). The American College of Surgeons Commission on Cancer has focused on the number of lymph nodes removed as a quality surrogate; however, we prefer and recommend using the International Association for the Study of Lung Cancer nodal maps, which focus on nodal stations, for pre- and intraoperative nodal staging. Although selective lobar-specific N2 nodal staging ${ }^{46}$ or N2 nodal sampling ${ }^{47}$ strategies appear to have oncologic equivalence to nodal dissection for clinical stage I lung cancer, we favor systematic mediastinal lymphadenectomy, as defined by ESTS guidelines, ${ }^{48}$ regardless of the surgical approach used. Logical exceptions to this approach include minimally invasive adenocarcinoma and adenocarcinoma in situ histologic subtypes and T1a tumors. Regardless of whether lymph nodes are sampled or dissected, we believe that systematic acquisition of mediastinal nodal tissue based on nodal station(s) is a useful quality metric, and, therefore, we recommend each program adopt a preferred approach and track adherence.

\section{Postoperative Quality Measures}

Morbidity and mortality. The outcome measures of morbidity and mortality are dependent on appropriate case selection, the need for induction therapy, surgical technique, and strategies to mitigate failure to rescue concerns. ${ }^{49}$ A quality program should track 30-day or in-hospital mortality as well as 90-day mortality following lung cancer resection. Some authors have questioned whether 30-day or in-hospital mortality should be used as a quality metric, on the basis of low occurrence rates and the fact that mortality doubles at 90 days, which suggests 
TABLE 1. Modified National Comprehensive Cancer Network guidelines for intraoperative management of patients with non-small cell lung cancer

Guideline

Anatomic resection is preferred for the majority of patients

For patients who undergo segmentectomy or wedge resection, the patient should have resection margins $\geq 2 \mathrm{~cm}$ or that are greater than or equal to the size of the nodule

Segmentectomy or wedge resection is appropriate for patients with poor pulmonary reserve and with peripheral nodule $\leq 2 \mathrm{~cm}$ with any of the following: pure adenocarcinoma in situ histologic subtype, nodule $\geq 50 \%$ ground glass appearance on computed tomography, or radiologic surveillance with long doubling time $(\geq 400 \mathrm{~d})$

Minimally invasive approaches should be performed in appropriate patients

$\mathrm{N} 1$ and $\mathrm{N} 2$ node assessment should be performed with a minimum of $3 \mathrm{~N} 2$ stations or with complete nodal dissection

Formal ipsilateral mediastinal lymph node dissection is indicated for patients undergoing resection for stage IIIA disease

Complete resection requires resection-free margins, systematic lymph node dissection or sampling, and appropriate mediastinal node dissection

it is not a worthwhile discriminator between good- and poor-performing programs. $^{50}$ In addition, relevant morbidities that influence quality of care and the patient experience, such as pneumonia, deep vein thrombosis or pulmonary emboli, reoperation, and persistent air leaks, should be measured and tracked. Using the STS database, Kozower and colleagues ${ }^{51}$ combined risk-adjusted morbidity and mortality into a 2-domain composite score to rate program performance. ${ }^{51}$ Although imperfect, morbidity and mortality metrics with appropriate reliability and clinical utility that are risk-stratified do exist and can serve as starting points for quality improvement projects or related initiatives for individual programs (Table 3).

Length of stay following lung cancer resection remains an important surrogate quality metric. Although surgical approach has no significant effect on mortality, the majority of the literature supports the perspective that minimally invasive approaches result in fewer complications and shorter length of stay, without increasing readmission rates. This suggests that increasing (and measuring) the percentage of minimally invasive approaches performed for early stage disease (stage I or stage II) as a process measure may result in decreased lengths of stay and improve value. The percentage of minimally invasive resections performed for clinical stage I lung cancer currently stands at $64 \%$ in the STS database, and this is now a metric that is captured and reported. ${ }^{51}$ Finally, exclusive of the development of perioperative complications, length of stay is strongly affected by patient comorbidities, age, and socioeconomic status. Length-of-stay metrics likely need to be riskstratified on the basis of these and other variables to be meaningful to a practicing surgeon.

Enhanced recovery after surgery. Initiated in the 1990s by Kehlet ${ }^{53}$ and others, enhanced recovery after surgery (ERAS) protocols are multimodality pathways designed to decrease the physiologic and psychological effects of surgery, reduce length of stay and complications, and facilitate recovery. The primary components of these process improvement programs are focused on preoperative nutrition, nonopioid analgesia, limited perioperative fluid administration, and early ambulation. ${ }^{54}$ Muehling and colleagues $^{55}$ investigated an ERAS protocol and found no significant reductions in mortality, readmission rates, or complications (excluding a reduction in pulmonary complications) ${ }^{55} \mathrm{~A}$ recent meta-analysis using a Cochrane risk-for-bias model resulted in low-quality evidence suggesting that an ERAS program for pulmonary resection reduces length of stay. ${ }^{56}$ However, costs were reduced in 2 of the 3 studies in which this was examined, and patientreported outcomes were also improved in the one study that examined this variable. ${ }^{56}$ In summary, the influence of ERAS programs on enhancing quality is understudied

TABLE 2. Minimum recommended surgical mediastinal lymph node staging quality parameters

\begin{tabular}{|c|c|c|c|c|c|}
\hline \multirow[b]{2}{*}{ Tumor location } & \multicolumn{5}{|c|}{ Guideline group and recommendations } \\
\hline & ACOSOG & $\mathrm{CoC}$ & ESTS & IASLC & $\mathrm{NCCN}$ \\
\hline \multicolumn{6}{|l|}{ Right lung } \\
\hline Upper & $2 \mathrm{R}, 4 \mathrm{R}, 7,10 \mathrm{R}$ & \multirow{3}{*}{$\begin{array}{l}\geq 10 \\
\text { nodes* }\end{array}$} & $2 \mathrm{R}, 4 \mathrm{R}, 7$ & $3,4 \mathrm{R}, 7$ & \multirow{3}{*}{$\geq 3 \mathrm{~N} 2$ stations } \\
\hline Middle & Same & & Same & Same & \\
\hline Lower & Same & & $4 \mathrm{R}, 7,8,9$ & $3,4 \mathrm{R}, 7,8,9$ & \\
\hline \multicolumn{6}{|l|}{ Left lung } \\
\hline Upper & $5,6,7,10 \mathrm{~L}$ & $\geq 10$ & $5,6,7$ & $3,5,6,7$ & \multirow{2}{*}{$\geq 3 \mathrm{~N} 2$ stations } \\
\hline Lower & Same & nodes* & $7,8,9$ & $7,8,9$ & \\
\hline
\end{tabular}

ACOSOG, American College of Surgeons Oncology Group; CoC, American College of Surgeons Commission on Cancer; ESTS, European Society of Thoracic Surgeons; $I A S L C$, International Association for the Study of Lung Cancer; $N C C N$, National Comprehensive Cancer Network; $R$, right; $L$, left. *No nodal station specification. Reprinted from reference 38, with permission from AME Publishing Company. 
TABLE 3. Major morbidity and mortality quality metrics following lobectomy for lung cancer

\begin{tabular}{lccc}
\hline & & \multicolumn{2}{c}{$\begin{array}{c}\text { Minimally invasive } \\
\text { approaches only } \dagger\end{array}$} \\
\cline { 3 - 4 } \multicolumn{1}{c}{ Variable } & All approaches* & VATS & RA-VATS \\
\hline No. of cases & 20,657 & 12,378 & 1220 \\
\hline Pneumonia & 4.3 & 3.3 & 2.7 \\
\hline ARDS & 0.7 & 0.5 & 0.2 \\
Pulmonary embolus & 0.5 & 0.5 & 0.3 \\
\hline Reintubation & 3.4 & 2.3 & 2.0 \\
Unexpected return to & 3.9 & 0.9 & 0.8 \\
\multicolumn{1}{c}{ operating room } & & & 0.4 \\
Myocardial infarction & 0.4 & 0.3 & $0.4-5)$ \\
Length of stay (d) & $4(3-7)$ & $4(3-6)$ & $4(2-5)$ \\
\hline Operative mortality & 1.7 & 0.8 & 0.6 \\
\hline
\end{tabular}

Values for number of cases are presented as $n$, values for length of stay are presented as median (interquartile range), and all other values are presented as \%. See Kozower and colleagues ${ }^{51}$ and Louie and colleagues. ${ }^{52}$ VATS, Video-assisted thoracic surgery; $R A$-VATS, robot-assisted video-assisted thoracic surgery; ARDS, acute respiratory distress syndrome. *Data are from the Society of Thoracic Surgeons-General Thoracic Surgery Database 2011 to 2014, for all approaches. †Data are from the Society of Thoracic Surgeons-General Thoracic Surgery Database 2009 to 2013, for minimally invasive approaches only.

in thoracic surgical oncology. Opportunities exist to perform well-designed randomized trials to clarify the role of ERAS programs in our specialty.

\section{Hospital Readmission}

Reduction of hospital readmission is a priority for surgeons; hospitals; insurers; and, most importantly, patients. An unintended consequence of efforts to reduce length of stay may be increased readmission rates, with most data suggesting a U-shaped relationship between length of stay and readmission rates. ${ }^{57}$ However, a recent study using the NCDB showed that early discharge strategies do not increase readmission rates among patients who have undergone open or minimally invasive lobectomy for lung cancer. $^{58}$ Several studies have examined hospital readmission rates following pulmonary resection. A recent article linked 3 administrative databases and found that the overall readmission rate in the Medicare population following lobectomy is $12 \% .{ }^{59}$ Hospital Quality Alliance surgical score, procedure volume, and 30-day surgical mortality were used to determine whether measures of surgical quality affected readmission rates. Hospital Quality Alliance surgical score is calculated according to the evidence-based Surgical Care Improvement Project process measures, which are designed to reduce perioperative surgical complications and are included in the Centers for Medicare and Medicaid Services Hospital Value-Based Purchasing program. ${ }^{59}$ For 1602 hospitals spanning both high- and low-volume centers ( $\mathrm{N}=24,316$ patients), only hospital volume was significantly associated with 30-day readmission rates following lobectomy. Another analysis of the SEER database revealed a $13 \%$ readmission rate following lung cancer resection, which was associated with a 6 -fold increase in 90-day mortality. ${ }^{50}$ Other groups have shown that the 90-day readmission rate following lung cancer resection is $21 \%$, with only $81 \%$ of patients discharged home after their index procedure ${ }^{60}$ Collectively, these data show that efforts to reduce hospital readmission following lung cancer resection are influenced by procedure type, hospital volume, patient socioeconomic status, discharge destination, and index procedure length of stay. Some of these risk factors may be modified, but many cannot be modified, which makes addressing this outcome metric challenging. Nonetheless, we believe that readmission rates following NSCLC resection should be considered a quality metric, and institutional rates should be tracked and analyzed.

\section{Consideration of Adjuvant Therapies}

Although it is not a primary focus of this review, appropriate referral for adjuvant therapies following lung cancer resection is an important element of lung cancer care. For instance, clear consensus-based guidelines exist both for referral for adjuvant chemotherapy for pathologic node-positive disease and for consideration of adjuvant radiation to the mediastinum for persistent or intraoperatively discovered $\mathrm{N} 2$ disease. ${ }^{13}$ Therefore, programmatic oncologic quality metrics to track appropriate and inappropriate referrals for adjuvant therapy and the number of patients who complete such therapy are important.

\section{CONCLUSIONS}

Quality in the surgical care of patients with lung cancer is a complicated, multidimensional, and moving target. There is an emerging body of evidence showing that an understanding of and adherence to known quality metrics in thoracic oncologic surgery results in improved patient outcomes. Some groups have developed systems to evaluate and improve quality, such as the Composite Performance Score. ${ }^{61}$ This concept was recently illustrated in a study by Samson and colleagues, ${ }^{62}$ who examined the use of 4 well-established quality metrics in the management of stage IIIA NSCLC. Adherence to all quality metrics resulted in a significant improvement in overall survival. ${ }^{62} \mathrm{~A}$ robust opportunity remains for thoracic oncologic surgeons to design and conduct quality initiatives and to report on how they influence the patient experience and patient outcomes. The structure to complete these types of projects is always multidisciplinary and is most commonly housed in a disease management team or related entity. Establishment of a quality thoracic surgical program begins with deciding what quality metrics are important to collect and analyze and are modifiable through practice changes, and then linking them to a desired outcome. The STS has 
suggested participation in a national or regional database as a quality metric, and there are clear benefits to benchmarking your program to others. Although the emerging relationship between quality and hospital volume is beyond the scope of this article, we believe that the highest-quality programs will have the best patient outcomes and value and that, when controlling for access, quality will be the ultimate driver of patient volumes.

\section{Conflict of Interest Statement}

Authors have nothing to disclose with regard to commercial support.

\section{References}

1. Farjah F, Detterbeck FC. What is quality, and can we define it in lung cancer? The case for quality improvement. Transl Lung Cancer Res. 2015;4:365-72.

2. Mariotto AB, Yabroff KR, Shao Y, Feuer EJ, Brown ML. Projections of the cost of cancer care in the United States: 2010-2020. J Natl Cancer Inst. 2011;103: 117-28.

3. Nardi EA, Wolfson JA, Rosen ST, Diasio RB, Gerson SL, Parker BA, et al. Value, access, and cost of cancer care delivery at academic cancer centers. J Natl Compr Canc Netw. 2016;14:837-47.

4. Darling G, Malthaner R, Dickie J, McKnight L, Nhan C, Hunter A, et al. Quality indicators for non-small cell lung cancer operations with use of a modified Delphi consensus process. Ann Thorac Surg. 2014;98:183-90.

5. Seder CW, Wright CD, Chang AC, Han JM, McDonald D, Kozower BD. The Society of Thoracic Surgeons General Thoracic Surgery Database update on outcomes and quality. Ann Thorac Surg. 2016;101:1646-54.

6. De Leyn P, Lardinois D, Van Schil P, Rami-Porta R, Passlick B, Zielinski M, et al European trends in preoperative and intraoperative nodal staging: ESTS guidelines. J Thorac Oncol. 2007;2:357-61.

7. Donabedian A. The quality of care. How can it be assessed? JAMA. 1988;260: 1743-8.

8. Mason DP, Subramanian S, Nowicki ER, Grab JD, Murthy SC, Rice TW, et al Impact of smoking cessation before resection of lung cancer: a Society of Thoracic Surgeons General Thoracic Surgery Database study. Ann Thorac Surg. 2009;88:362-70.

9. Wright CD, Gaissert HA, Grab JD, O’Brien SM, Peterson ED, Allen MS. Predictors of prolonged length of stay after lobectomy for lung cancer: a Society of Thoracic Surgeons General Thoracic Surgery Database risk-adjustment model. Ann Thorac Surg. 2008;85:1857-65.

10. Leone FT, Evers-Casey S, Toll BA, Vachani A. Treatment of tobacco use in lung cancer: diagnosis and management of lung cancer, 3rd ed: American College of Chest Physicians evidence-based clinical practice guidelines. Chest. 2013;143: e61S-77S.

11. Zaman M, Bilal H, Mahmood S, Tang A. Does getting smokers to stop smoking before lung resections reduce their risk? Interact Cardiovasc Thorac Surg. 2012; 14:320-3.

12. Brunelli A, Kim AW, Berger KI, Addrizzo-Harris DJ. Physiologic evaluation of the patient with lung cancer being considered for resectional surgery: diagnosis and management of lung cancer, 3rd ed: American College of Chest Physicians evidence-based clinical practice guidelines. Chest. 2013;143:e166S-90S.

13. National Comprehensive Cancer Network. NCCN clinical practice guidelines in oncology: non-small cell lung cancer. Version 3.2017. Available at: https://www. nccn.org/professionals/physician_gls/f_guidelines_nojava.asp. Accessed June 12, 2017.

14. McFalls EO, Ward HB, Moritz TE, Goldman S, Krupski WC, Littooy F, et al. Coronary-artery revascularization before elective major vascular surgery. $N$ Engl J Med. 2004:351:2795-804.

15. Fleisher LA, Fleischmann KE, Auerbach AD, Barnason SA, Beckman JA, Bozkurt B, et al. 2014 ACC/AHA guideline on perioperative cardiovascular evaluation and management of patients undergoing noncardiac surgery: a report of the American College of Cardiology/American Heart Association Task Force on Practice Guidelines. Circulation. 2014;130:e278-333.

16. Ost DE, Niu J, Elting LS, Buchholz TA, Giordano SH. Quality gaps and comparative effectiveness in lung cancer staging and diagnosis. Chest. 2014;145:331-45.
17. Farjah F, Flum DR, Ramsey SD, Heagerty PJ, Symons RG, Wood DE. Multi-modality mediastinal staging for lung cancer among medicare beneficiaries. $J$ Thorac Oncol. 2009; 4:355-63.

18. National Comprehensive Cancer Network. NCCN clinical practice guidelines in oncology: lung cancer screening. Version I. 2017. Available at: www.nccn.org/ professionals/physician_gls/f_guidelines_nojava.asp. Accessed June 12, 2017.

19. De Leyn P, Dooms C, Kuzdzal J, Lardinois D, Passlick B, Rami-Porta R, et al. Revised ESTS guidelines for preoperative mediastinal lymph node staging for non-small-cell lung cancer. Eur J Cardiothorac Surg. 2014;45:787-98.

20. Park HS, Detterbeck FC, Boffa DJ, Kim AW. Impact of hospital volume of thoracoscopic lobectomy on primary lung cancer outcomes. Ann Thorac Surg. 2012; 93:372-9.

21. Cao C, Manganas C, Ang SC, Yan TD. A meta-analysis of unmatched and matched patients comparing video-assisted thoracoscopic lobectomy and conventional open lobectomy. Ann Cardiothorac Surg. 2012;1:16-23.

22. Paul S, Altorki NK, Sheng S, Lee PC, Harpole DH, Onaitis MW, et al. Thoracoscopic lobectomy is associated with lower morbidity than open lobectomy: a propensity-matched analysis from the STS database. J Thorac Cardiovasc Surg. 2010;139:366-78.

23. Kozower BD, Sheng S, O'Brien SM, Liptay MJ, Lau CL, Jones DR, et al. STS database risk models: predictors of mortality and major morbidity for lung cancer resection. Ann Thorac Surg. 2010;90:875-81.

24. Nwogu CE, D'Cunha J, Pang H, Gu L, Wang X, Richards WG, et al. VATS lobectomy has better perioperative outcomes than open lobectomy: CALGB 31001, an ancillary analysis of CALGB 140202 (Alliance). Ann Thorac Surg. 2015;99:399-405.

25. Farjah F, Backhus LM, Varghese TK, Mulligan MS, Cheng AM, AlfonsoCristancho R, et al. Ninety-day costs of video-assisted thoracic surgery versus open lobectomy for lung cancer. Ann Thorac Surg. 2014;98:191-6.

26. Swanson SJ, Miller DL, McKenna RJ Jr, Howington J, Marshall MB, Yoo AC, et al. Comparing robot-assisted thoracic surgical lobectomy with conventional video-assisted thoracic surgical lobectomy and wedge resection: esults from a multihospital database (Premier). J Thorac Cardiovasc Surg. 2014;147:929-37.

27. Ye X, Xie L, Chen G, Tang JM, Ben XS. Robotic thoracic surgery versus videoassisted thoracic surgery for lung cancer: a meta-analysis. Interact Cardiovasc Thorac Surg. 2015;21:409-14.

28. Riquet M, Achour K, Foucault C, Le Pimpec Barthes F, Dujon A, Cazes A. Microscopic residual disease after resection for lung cancer: a multifaceted but poor factor of prognosis. Ann Thorac Surg. 2010;89:870-5.

29. Dall K, Ford C, Fisher R, Dunning J. Is there a survival advantage of incomplete resection of non-small-cell lung cancer that is found to be unresectable at thoracotomy? Interact Cardiovasc Thorac Surg. 2013;16:529-32.

30. Ginsberg RJ, Rubinstein LV. Randomized trial of lobectomy versus limited resection for T1 N0 non-small cell lung cancer. Lung Cancer Study Group. Ann Thorac Surg. 1995;60:615-22.

31. Dai C, Shen J, Ren Y, Zhong S, Zheng H, He J, et al. Choice of surgical procedure for patients with non-small-cell lung cancer $</=1 \mathrm{~cm}$ or $>1$ to $2 \mathrm{~cm}$ among lobectomy, segmentectomy, and wedge resection: a population-based study. J Clin Oncol. 2016;34:3175-82.

32. Khullar OV, Liu Y, Gillespie T, Higgins KA, Ramalingam S, Lipscomb J, et al. Survival after sublobar resection versus lobectomy for clinical stage IA lung cancer: an analysis from the National Cancer Data Base. J Thorac Oncol. 2015;10:1625-33.

33. Cao C, Chandrakumar D, Gupta S, Yan TD, Tian DH. Could less be more? A systematic review and meta-analysis of sublobar resections versus lobectomy for non-small cell lung cancer according to patient selection. Lung Cancer. 2015; 89:121-32.

34. Port JL, Parashar B, Osakwe N, Nasar A, Lee PC, Paul S, et al. A propensitymatched analysis of wedge resection and stereotactic body radiotherapy for early stage lung cancer. Ann Thorac Surg. 2014;98:1152-9.

35. Howington JA, Blum MG, Chang AC, Balekian AA, Murthy SC. Treatment of stage I and II non-small cell lung cancer: diagnosis and management of lung cancer, 3rd ed: American College of Chest Physicians evidence-based clinical practice guidelines. Chest. 2013;143:e278S-313S.

36. Mohiuddin K, Haneuse S, Sofer T, Gill R, Jaklitsch MT, Colson YL, et al. Relationship between margin distance and local recurrence among patients undergoing wedge resection for small $(</=2 \mathrm{~cm})$ non-small cell lung cancer. $J$ Thorac Cardiovasc Surg. 2014; 147:1169-75.

37. Sienel W, Dango S, Kirschbaum A, Cucuruz B, Horth W, Stremmel C, et al. Sublobar resections in stage IA non-small cell lung cancer: segmentectomies result in significantly better cancer-related survival than wedge resections. Eur J Cardiothorac Surg. 2008;33:728-34. 
38. Osarogiagbon RU, Hilsenbeck HL, Sales EW, Berry A, Jarrett RW Jr, Giampapa CS, et al. Improving the pathologic evaluation of lung cancer resection specimens. Transl Lung Cancer Res. 2015;4:432-7.

39. Varlotto JM, Recht A, Nikolov M, Flickinger JC, Decamp MM. Extent of lymphadenectomy and outcome for patients with stage I nonsmall cell lung cancer. Cancer. 2009;115:851-8.

40. Allen JW, Farooq A, O'Brien TF, Osarogiagbon RU. Quality of surgical resection for nonsmall cell lung cancer in a US metropolitan area. Cancer. 2011;117:134-42.

41. Osarogiagbon RU, Yu X. Nonexamination of lymph nodes and survival after resection of non-small cell lung cancer. Ann Thorac Surg. 2013;96:1178-89.

42. Ou SH, Zell JA. Prognostic significance of the number of lymph nodes removed at lobectomy in stage IA non-small cell lung cancer. J Thorac Oncol. 2008;3: 880-6.

43. Osarogiagbon RU, Allen JW, Farooq A, Berry A, O’Brien T. Pathologic lymph node staging practice and stage-predicted survival after resection of lung cancer. Ann Thorac Surg. 2011;91:1486-92.

44. Little AG, Rusch VW, Bonner JA, Gaspar LE, Green MR, Webb WR, et al. Patterns of surgical care of lung cancer patients. Ann Thorac Surg. 2005;80:2051-6.

45. Osarogiagbon RU, Yu X. Mediastinal lymph node examination and survival in resected early-stage non-small-cell lung cancer in the surveillance, epidemiology, and end results database. J Thorac Oncol. 2012;7:1798-806.

46. Adachi H, Sakamaki K, Nishii T, Yamamoto T, Nagashima T, Ishikawa Y, et al. Lobe-specific lymph node dissection as a standard procedure in surgery for nonsmall cell lung cancer: a propensity score matching study. J Thorac Oncol. 2017; 12:85-93.

47. Allen MS, Darling GE, Pechet TT, Mitchell JD, Herndon JE 2nd, Landreneau RJ, et al. Morbidity and mortality of major pulmonary resections in patients with early-stage lung cancer: initial results of the randomized, prospective ACOSOG Z0030 trial. Ann Thorac Surg. 2006;81:1013-9.

48. Lardinois D, De Leyn P, Van Schil P, Porta RR, Waller D, Passlick B, et al. ESTS guidelines for intraoperative lymph node staging in non-small cell lung cancer. Eur J Cardiothorac Surg. 2006;30:787-92.

49. Farjah F, Backhus L, Cheng A, Englum B, Kim S, Saha-Chaudhuri P, et al. Failure to rescue and pulmonary resection for lung cancer. J Thorac Cardiovasc Surg. 2015;149:1365-71.

50. Hu Y, McMurry TL, Wells KM, Isbell JM, Stukenborg GJ, Kozower BD. Postoperative mortality is an inadequate quality indicator for lung cancer resection. Ann Thorac Surg. 2014;97:973-9.
51. Kozower BD, O’Brien SM, Kosinski AS, Magee MJ, Dokholyan R, Jacobs JP, et al. The Society of Thoracic Surgeons composite score for rat ing program performance for lobectomy for lung cancer. Ann Thorac Surg. 2016;101:1379-86

52. Louie BE, Wilson JL, Kim S, Cerfolio RJ, Park BJ, Farivar AS, et al. Comparison of video-assisted thoracoscopic surgery and robotic approaches for clinical stage I and stage II non-small cell lung cancer using the Society of Thoracic Surgeons database. Ann Thorac Surg. 2016;102:917-24.

53. Kehlet H. Multimodal approach to control postoperative pathophysiology and rehabilitation. Br J Anaesth. 1997:78:606-17.

54. Melnyk M, Casey RG, Black P, Koupparis AJ. Enhanced recovery after surgery (ERAS) protocols: time to change practice? Can Urol Assoc J. 2011;5:342-8.

55. Muehling BM, Halter GL, Schelzig H, Meierhenrich R, Steffen P, SunderPlassmann L, et al. Reduction of postoperative pulmonary complications after lung surgery using a fast track clinical pathway. Eur J Cardiothorac Surg. 2008;34:174-80.

56. Fiore JF Jr, Bejjani J, Conrad K, Niculiseanu P, Landry T, Lee L, et al. Systematic review of the influence of enhanced recovery pathways in elective lung resection. J Thorac Cardiovasc Surg. 2016;151:708-15.e706.

57. Freeman RK, Dilts JR, Ascioti AJ, Dake M, Mahidhara RS. A comparison of length of stay, readmission rate, and facility reimbursement after lobectomy of the lung. Ann Thorac Surg. 2013;96:1740-5.

58. Rosen JE, Salazar MC, Dharmarajan K, Kim AW, Detterbeck FC, Boffa DJ Length of stay from the hospital perspective: practice of early discharge is no associated with increased readmission risk after lung cancer surgery. Ann Surg. 2016 [Epub ahead of print].

59. Tsai TC, Joynt KE, Orav EJ, Gawande AA, Jha AK. Variation in surgicalreadmission rates and quality of hospital care. N Engl J Med. 2013;369:1134-42.

60. Stitzenberg KB, Chang Y, Smith AB, Nielsen ME. Exploring the burden of inpatient readmissions after major cancer surgery. J Clin Oncol. 2015;33: 455-64.

61. Brunelli A, Rocco G, Van Raemdonck D, Varela G, Dahan M. Lessons learned from the European Thoracic Surgery Database: the Composite Performance Score. Eur J Surg Oncol. 2010;3(Suppl 1):S93-9.

62. Samson P, Crabtree T, Robinson CG, Morgensztern D, Broderick SR, Kreisel D, et al. Surgical quality measures in clinical stage IIIA non-small cell lung cancer are associated with improved survival. J Thorac Cardiovasc Surg. 2017 [In review]. 